Article

\title{
Improvement of the Corrosion Resistance of Biomedical Zr-Ti Alloys Using a Thermal Oxidation Treatment
}

\author{
Javier Izquierdo ${ }^{1,2} \oplus$, Daniel Mareci ${ }^{3,+}{ }^{+}$Georgiana Bolat ${ }^{3}$, Juan J. Santana ${ }^{4} \oplus$, \\ Raquel Rodríguez-Raposo ${ }^{1}$, Luis C. Fernández-Mérida ${ }^{1}$, Liviu Burtan ${ }^{5, *}$, Lucia C. Trincă 6 (D) and \\ Ricardo M. Souto $1,2, *$ (D) \\ 1 Institute of Material Science and Nanotechnology, Universidad de La Laguna, E-38200 La Laguna (Tenerife, \\ Canary Islands), Spain; jizquier@ull.edu.es (J.I.); rrraposo@ull.edu.es (R.R.-R.); \\ lfdezmer@ull.edu.es (L.C.F.-M.) \\ 2 Department of Chemistry, Universidad de La Laguna, E-38200 La Laguna (Tenerife, Canary Islands), Spain \\ 3 Department of Chemical Engineering, Technical University "Gheorghe Asachi" of Iasi, Faculty of Chemical \\ Engineering and Environmental Protection, D. Mangeron, 700050 Iasi, Romania; \\ danmareci@yahoo.com (D.M.); georgiana20022@yahoo.com (G.B.) \\ 4 Department of Process Engineering, Universidad de Las Palmas de Gran Canaria, Campus Universitario de \\ Tafira, E-35017 Las Palmas de Gran Canaria, Spain; juan.santana@ulpgc.es \\ 5 Clinics Department, "Ion Ionescu de la Brad” University of Agricultural Sciences and Veterinary Medicine, \\ Faculty of Horticulture, Str. Aleea M. Sadoveanu, no. 8, 700490 Iasi, Romania \\ 6 Exact Sciences Department, "Ion Ionescu de la Brad" University of Agricultural Sciences and Veterinary \\ Medicine, Faculty of Horticulture, Str. Aleea M. Sadoveanu, no. 3, 700490 Iasi, Romania; lctrinca@uaiasi.ro \\ * Correspondence: blmv2018@yahoo.com (L.B.); rsouto@ull.es (R.M.S.); \\ Tel.: +40-232-407547 (L.B.); +34-922-318067 (R.M.S.) \\ + Deceased on 8 January 2017.
}

Received: 28 December 2019; Accepted: 20 January 2020; Published: 22 January 2020

\begin{abstract}
Binary Zr-Ti alloys spontaneously develop a tenacious and compact oxide layer when their fresh surface is exposed either to air or to aqueous environments. Electrochemical impedance spectroscopy (EIS) analysis of Zr-45Ti, Zr-25Ti, and Zr-5Ti exposed to simulated physiological solutions at $37^{\circ} \mathrm{C}$ evidences the formation of a non-sealing bilayer oxide film that accounts for the corrosion resistance of the materials. Unfortunately, these oxide layers may undergo breakdown and stable pitting corrosion regimes at anodic potentials within the range of those experienced in the human body under stress and surgical conditions. Improved corrosion resistance has been achieved by prior treatment of these alloys using thermal oxidation in air. EIS was employed to measure the corrosion resistance of the $\mathrm{Zr}$-Ti alloys in simulated physiological solutions of a wide $\mathrm{pH}$ range (namely $3 \leq \mathrm{pH} \leq 8$ ) at $37^{\circ} \mathrm{C}$, and the best results were obtained for the alloys pre-treated at $500{ }^{\circ} \mathrm{C}$. The formation of the passivating oxide layers in simulated physiological solution was monitored in situ using scanning electrochemical microscopy (SECM), finding a transition from an electrochemically active surface, characteristic of the bare metal, to the heterogeneous formation of oxide layers behaving as insulating surfaces towards electron transfer reactions.
\end{abstract}

Keywords: Zr-Ti binary alloys; biomaterial; surface modification; corrosion resistance; electrochemical techniques

\section{Introduction}

Metallic biomaterials are used as prostheses in applications that require weight-bearing or to face mechanical forces, as in the case of skeletal elements or dental applications [1]. However, pure metals 
do not have the strength, elasticity, ductility, and purity required by the different types of implants currently used in traumatology and orthopedics. For this reason, the addition of one or more alloying elements to the base metal is commonly conducted, thus modifying the crystalline structure, and therefore its physical and mechanical properties.

Titanium and its alloys are of particular interest for biomedical applications due to their exceptional biocompatibility and high resistance to corrosion [2-4]. In comparison with other metallic biomaterials such as stainless steel and $\mathrm{CoCr}$ alloys, titanium-based materials exhibit similar strength, lower weight, and reduced elastic modulus (55 to $100 \mathrm{GPa}$ ), closer to those found in bone tissues (<30 GPa) [4]. Osseointegration and enhanced biocompatibility have long been observed in Ti and Ti-based materials. Ti stability in the human body is conferred by the formation of a surface layer of titanium oxides (mainly $\mathrm{TiO}_{2}$ ) that passivates the material, protecting it from the attack of oxidizing agents $[5,6]$. Yet, concerns have been raised due to the nucleation of non-propagating pits on titanium exposed to simulated physiological conditions, estimated in 60-120 metastable pits per second and square centimeter [7]. Due to its improved anticorrosion resistance, the most common form of titanium used in orthopedic and dental implants is the Ti-6Al-4V alloy in its extra-low interstitial form, in which the oxygen concentration is kept very low to avoid its embrittlement and maximize its strength and ductility. Despite the clinical evidence of the excellent biocompatibility of this alloy, concerns have arisen about the release of cytotoxic elements such as vanadium $[8,9]$ and possibly aluminum $[10,11]$, as they can cause local and systemic problems. These concerns have motivated the search of alternative alloying elements, currently being investigated for titanium.

Although some binary Ti-Zr alloys -with Ti as the main component- have been adopted in the last decade for dental clinical applications [12,13], the same has not happened with binary Zr-Ti alloys, where $\mathrm{Zr}$ is the main component. Nonetheless, several studies correlated composition and structure with mechanical properties [14-16], and other works reported interesting corrosion resistance properties [17-22]. To date, the optimal ratio between $\mathrm{Ti}$ and $\mathrm{Zr}$ is still under investigation in order to combine mechanical properties similar to the host tissue where it will be implanted, a greater resistance against corrosion in the physiological environment, and good biological activity [23]. Upon contact with the biological fluids, at the surface of the implantable devices, both in vivo and in vitro, there is a sequence of physicochemical processes [24] that determine the structural and compositional changes of the superficial layers.

Passive layers with more insulating characteristics towards electron transfer are developed at the surface of the Zr-Ti alloys [19] compared to pure Zr, thus greatly reducing the greater susceptibility of $\mathrm{Zr}$ to localized corrosion induced by chloride ions compared to Ti $[25,26]$. Yet, passive layer breakdown in simulated physiological environment was reported for $\mathrm{Zr}$-Ti alloys with titanium contents smaller than $45 \mathrm{wt} . \%$. [19], when subjected to anodic polarization at potential values that have been reported to eventually develop in the human body [27]. The stability of passivating oxide layers on metals and alloys can be greatly improved using surface modification treatments [28-30]. In particular, thermal oxidation in air at elevated temperature has been shown to be effective in the case of Zr-Ti alloys [31-33].

The main aim of this study was to investigate in vitro the corrosion resistance of thermally-oxidized $\mathrm{Zr}$-Ti alloys as to optimize the processing conditions that lead to the development of a more stable and corrosion resistant surface oxide layer in simulated physiological environments of varying $\mathrm{pH}$. The $\mathrm{pH}$ of the environment was modified as to encompass the $\mathrm{pH}$ range that can be experienced in the event of inflammatory and surgical conditions [20]. Conventional electrochemical techniques were employed to characterize the corrosion resistance of the surface films. In addition, a microelectrochemical investigation was undertaken using the scanning electrochemical microscope (SECM) as to characterize the insulating properties of the heterogeneous surface film formed on $\mathrm{Zr}$-Ti alloys under the optimized thermal oxidation treatment. The SECM technique in the feedback mode enables monitoring of the evolution of the surface during the development of the insulating layer in the early stages of in vitro immersion. Hence, information on the heterogeneously distributed electron exchange ability of the biomaterials, previously treated using optimized surface processing procedures, is reported. In 
this way, spatially-resolved chemical monitoring of the surface films in the simulated physiological environment was performed [34].

\section{Materials and Methods}

\subsection{Materials and Sample Preparation}

The primary substrates employed in this work were three $\mathrm{Zr}$-Ti alloys with different titanium contents up to ca. $45 \%$, produced at ZIROM SA (Giurgiu, Romania) using an electron beam furnace. The melting process was repeated for three times to homogenize the chemical compositions of ingots, and their chemical compositions are presented in Table 1. The structural characterization, surface composition and morphology of the as cast alloys have been reported elsewhere [18]. Cylindrical ingot samples with $8 \mathrm{~mm}$ diameter and $8 \mathrm{~mm}$ height were ground to a 2000 grit finish with silicon carbide paper (Struers, Cleveland, OH, USA), ultrasonically cleaned in ultrapure deionized water (Millipore, Burlington, MA, USA; resistivity, $18.2 \mathrm{M} \Omega \mathrm{cm}$ ), degreased in ethanol, dried in air, and then oxidized in air in a range of temperatures between 100 and $600{ }^{\circ} \mathrm{C}$ for $4 \mathrm{~h}$. Neither significant roughening nor enrichment in either of the metal constituents is expected, and only $\mathrm{ZrO}_{2}$ and $\mathrm{TiO}_{2}$ oxides are assumed to be developed according to previous SEM-EDX and XRD observations [31].

Table 1. Chemical composition of the binary Zr-Ti alloys under investigation

\begin{tabular}{cccccccc}
\hline $\begin{array}{c}\text { Alloy/Element } \\
\text { (wt.\%) }\end{array}$ & Zr & Ti & Sn & Mo & Nb & Fe & Cr \\
\hline Zr-5Ti & 93.69 & 4.23 & 0.99 & 0.85 & 0.50 & 0.20 & 0.04 \\
Zr-25Ti & 75.55 & 22.12 & 0.81 & 0.82 & 0.45 & 0.20 & 0.05 \\
Zr-45Ti & 56.76 & 42.12 & 0.30 & 0.50 & 0.14 & 0.14 & 0.04 \\
\hline
\end{tabular}

\subsection{Corrosion Tests}

Conventional electrochemical experiments were performed in modified phosphate buffered saline (PBS) solution to cover the $3 \leq \mathrm{pH} \leq 8$ range. All reagents were supplied by Sigma-Aldrich (San Luis, $\mathrm{MO}, \mathrm{USA}$ ). The actual PBS solution contained $8 \mathrm{~g} \mathrm{NaCl}+0.2 \mathrm{~g} \mathrm{KCl}+1.44 \mathrm{~g} \mathrm{Na}_{2} \mathrm{HPO}_{4}+0.24 \mathrm{~g} \mathrm{KH}_{2} \mathrm{PO}_{4}$ dissolved in $800 \mathrm{~mL}$ ultrapure deionized $\mathrm{H}_{2} \mathrm{O}$, the $\mathrm{pH}$ was adjusted to 7.4 with $\mathrm{HCl}$, and ultrapure deionized $\mathrm{H}_{2} \mathrm{O}$ was added to adjust the volume to 1L. $\mathrm{pH}$ adjustment was performed using controlled additions of $\mathrm{HCl}$ or $\mathrm{NaOH}$ solution as required.

Electrochemical measurements were performed with a PARSTAT 4000 potentiostat (Princeton Applied Research, Princeton, NJ, USA). A three-electrode cell configuration was adopted with the $\mathrm{Zr}$-Ti alloy samples as working electrodes, a saturated calomel electrode (SCE) as reference, and a platinum mesh as auxiliary electrode. The temperature of the electrochemical cell was maintained at $37 \pm 1{ }^{\circ} \mathrm{C}$. The samples were left unpolarized in the test solutions to spontaneously attain their open circuit potential (OCP). The impedance spectra were recorded using a perturbation AC amplitude of $\pm 10 \mathrm{mV}$ (vs. OCP), and a frequency range from $100 \mathrm{kHz}$ to $15 \mathrm{mHz}$. EIS data were analyzed and fitted to an electrical equivalent circuit (EC) with ZSimpWin software (Princeton Applied Research, Princeton, NJ, USA).

\subsection{Scanning Electrochemical Microscopy (SECM)}

The SECM experiments were performed using a Sensolytics instrument (Bochum, Germany) controlled with a personal computer. The specimens were mounted horizontally facing upwards at the bottom of a Sensolytics cell designed to control the temperature at $37 \pm 1{ }^{\circ} \mathrm{C}$. The cell was equipped with an $\mathrm{Ag} / \mathrm{AgCl} / \mathrm{KCl}(3 \mathrm{M})$ reference electrode and a platinum auxiliary electrode. A $10 \mu \mathrm{m}$ diameter Pt microelectrode was employed as tip. The electrochemical cell was located inside a Faraday cage. Tip microelectrodes were made from $10 \mu \mathrm{m}$ platinum wires sealed in glass. $0.5 \mathrm{mM}$ ferrocene-methanol (Fc) was added to the Ringer's solution (i.e., $0.147 \mathrm{M} \mathrm{NaCl}+0.00432 \mathrm{M} \mathrm{CaCl}_{2}+0.00404 \mathrm{M} \mathrm{KCl}$ 
acidified with added $\mathrm{HCl}$ ) to act as electrochemical mediator at the tip. To enable the oxidation of the ferrocene-methanol to ferrocenium ion $\left(\mathrm{F}_{\mathrm{C}+}\right)$, the tip was kept at a constant potential of $+0.50 \mathrm{~V}$ vs. $\mathrm{Ag} / \mathrm{AgCl} /(3 \mathrm{M}) \mathrm{KCl}$. The micromanipulator stand of the SECM instrument was used to position the microelectrode tip in relation to the sample. Measurements were performed vertically (Z-approach curves) while approaching the $\mathrm{Pt}$ microelectrode towards the sample over $24 \mathrm{~h}$, in order to monitor the formation of the passive layer; and horizontally (2-D scans). The 2-D images were recorded at an approximate tip-to-substrate distance of $15 \mu \mathrm{m}$ covering an area of $500 \times 500 \mu \mathrm{m}^{2}$ at a scanning rate of $25 \mu \mathrm{m} \mathrm{s}^{-1}$ and $10 \mu \mathrm{m}$ lateral resolution (total scan duration $16-18 \mathrm{~min}$ ).

\section{Results and Discussion}

\subsection{In Vitro Corrosion Testing of the Zr-Ti Alloys}

The optimum pretreatment conditioning for the Zr-Ti alloys was selected using conventional electrochemical characterization in terms of providing the highest corrosion resistance to the materials. Electrochemical tests were done in phosphate buffer saline (PBS) at $\mathrm{pH}$ values ranging between 3 and 8 in order to simulate the full $\mathrm{pH}$ range that may occur in bone healing after implantation surgery [20], as well as to optimize the thermal oxidation conditions in a typical simulated body fluid. The corrosion resistance characteristics of the $\mathrm{Zr}$-Ti alloys subjected to thermal oxidation in air at different processing temperatures were quantified using electrochemical impedance spectroscopy (EIS) during exposure at the various test electrolytes. Figure 1 illustrates the EIS Bode diagrams recorded after 1-day exposure in non-modified PBS solution for the three $\mathrm{Zr}$-Ti alloys thermally oxidized at $500^{\circ} \mathrm{C}$ for $4 \mathrm{~h}$. From a cursory inspection of the spectra, the occurrence of two time-constants in the spectra can be observed, and they could be satisfactorily fitted using the equivalent circuit shown in Figure 2 based on a two-layer model for the surface film. The proposed EC is similar to that reported for titanium and titanium-based alloys in previous studies [6,35-38], as well as for the three as-cast Zr-Ti alloys in Ringer's solution [19]. $R_{\text {sol }}$ relates to the resistance of the solution, $R_{\mathrm{ct}}$ and $Q_{\mathrm{dL}}$ account for the reactions at the passive layer/solution interface, and $R_{\mathrm{ox}}$ and $Q_{\mathrm{ox}}$ to the properties of the oxide films formed on these alloys behaving as compact layers. The constant phase elements $Q_{\mathrm{dL}}$ and $Q_{\mathrm{ox}}$ were employed instead of a capacitor owing to dispersion effects arising from the microscopic roughness of the alloy surfaces.
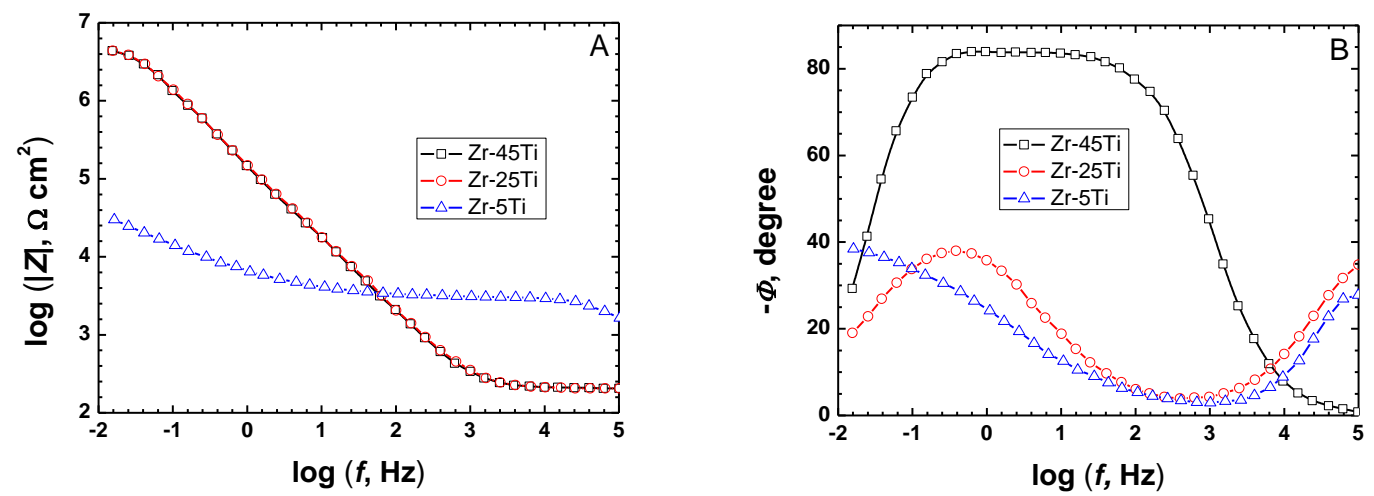

Figure 1. Bode plots acquired by EIS on binary Zr-Ti alloys (oxidized in air at $500{ }^{\circ} \mathrm{C}$ for $4 \mathrm{~h}$ ) after 1-day immersion in PBS at $37^{\circ} \mathrm{C}$. (A) Bode-amplitude, and (B) Bode-phase diagrams. 


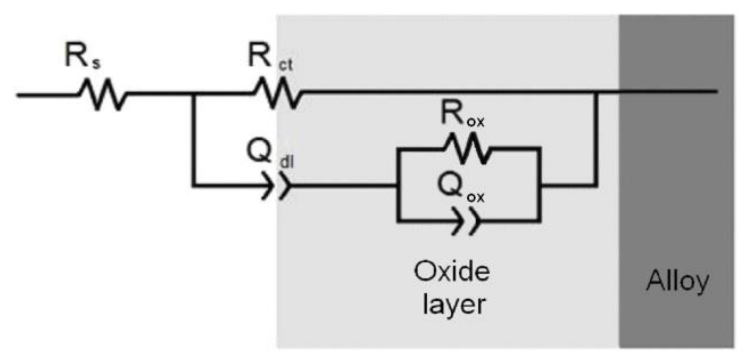

Figure 2. Equivalent electric circuit employed to fit the experimental EIS spectra.

For the sake of easier inter-comparison, a single parameter related to the corrosion resistance of the samples can be derived from the EIS data, namely the polarization resistance, $R_{\mathrm{p}}$. For the equivalent circuit in Figure 2, $R_{\mathrm{p}}$ can be calculated using the equation

$$
\frac{1}{R_{\mathrm{p}}} \cong \frac{1}{R_{\mathrm{ct}}}+\frac{1}{R_{\mathrm{ox}}}
$$

Average $R_{\mathrm{p}}$ values recorded for the three $\mathrm{Zr}$-Ti alloys immersed in modified PBS solutions within the $3 \leq \mathrm{pH} \leq 8$ range and for thermal oxidation temperatures between 100 and $600{ }^{\circ} \mathrm{C}$ are listed in Tables 2-7. Variations in the corrosion resistance of the $\mathrm{Zr}-\mathrm{Ti}$ alloys can be derived as a function of the alloy composition, the temperature of the thermal oxidation process, and the acidity of the simulated physiological environment. In general, the binary alloy showing the highest corrosion resistance was $\mathrm{Zr}$-45Ti regardless the $\mathrm{pH}$ of the environment for a given surface modification condition. This feature confirmed the beneficial effect of titanium addition to zirconium for the formation of more compact and tenacious oxide films on the surface of the material, as it was previously observed for the as cast $\mathrm{Zr}$ - $\mathrm{Ti}$ alloys [19]. Although Zr-5Ti exhibited the lowest $R_{\mathrm{p}}$ values, surface modification by thermal oxidation in air was found to greatly improve the electrochemical characteristics of this material as well.

Table 2. Values of the polarization resistance (in $\mathrm{M} \Omega \cdot \mathrm{cm}^{2}$ ) as a function of immersion time of thermally oxidized $\mathrm{Zr}$-Ti alloys in phosphate buffered saline solution acidified at $\mathrm{pH}=3.0 \pm 0.1$

\begin{tabular}{|c|c|c|c|c|c|c|}
\hline \multirow{2}{*}{ Immersion Time/h } & \multicolumn{6}{|c|}{ Oxidation Temperature $/{ }^{\circ} \mathrm{C}$} \\
\hline & 100 & 200 & 300 & 400 & 500 & 600 \\
\hline \multicolumn{7}{|c|}{ Zr-5Ti } \\
\hline 1 & 0.20 & 0.24 & 0.24 & 0.31 & 0.31 & 0.069 \\
\hline 2 & 0.19 & 0.22 & 0.22 & 0.33 & 0.29 & 0.067 \\
\hline 10 & 0.17 & 0.20 & 0.22 & 0.34 & 0.28 & 0.066 \\
\hline \multicolumn{7}{|c|}{ Zr-25Ti } \\
\hline 1 & 0.22 & 0.25 & 0.26 & 0.32 & 0.30 & 0.074 \\
\hline 2 & 0.21 & 0.24 & 0.25 & 0.33 & 0.28 & 0.072 \\
\hline 10 & 0.21 & 0.22 & 0.25 & 0.35 & 0.28 & 0.070 \\
\hline \multicolumn{7}{|c|}{ Zr-45Ti } \\
\hline 1 & 0.27 & 0.32 & 0.33 & 0.37 & 0.30 & 0.079 \\
\hline 2 & 0.25 & 0.30 & 0.31 & 0.39 & 0.29 & 0.077 \\
\hline 10 & 0.24 & 0.30 & 0.30 & 0.40 & 0.28 & 0.075 \\
\hline
\end{tabular}


Table 3. Values of the polarization resistance (in $\mathrm{M} \Omega \cdot \mathrm{cm}^{2}$ ) as a function of immersion time of thermally oxidized $\mathrm{Zr}$-Ti alloys in phosphate buffered saline solution acidified at $\mathrm{pH}=4.1 \pm 0.1$

\begin{tabular}{|c|c|c|c|c|c|c|}
\hline \multirow{2}{*}{ Immersion Time/h } & \multicolumn{6}{|c|}{ Oxidation Temperature $/{ }^{\circ} \mathrm{C}$} \\
\hline & 100 & 200 & 300 & 400 & 500 & 600 \\
\hline \multicolumn{7}{|c|}{ Zr-5Ti } \\
\hline 1 & 0.22 & 0.25 & 0.25 & 0.32 & 0.31 & 0.072 \\
\hline 2 & 0.21 & 0.23 & 0.24 & 0.34 & 0.30 & 0.070 \\
\hline 10 & 0.19 & 0.22 & 0.22 & 0.34 & 0.28 & 0.067 \\
\hline \multicolumn{7}{|c|}{ Zr-25Ti } \\
\hline 1 & 0.24 & 0.27 & 0.28 & 0.32 & 0.31 & 0.076 \\
\hline 2 & 0.24 & 0.26 & 0.28 & 0.34 & 0.29 & 0.074 \\
\hline 10 & 0.23 & 0.26 & 0.27 & 0.35 & 0.29 & 0.071 \\
\hline \multicolumn{7}{|c|}{ Zr-45Ti } \\
\hline 1 & 0.29 & 0.34 & 0.35 & 0.39 & 0.31 & 0.082 \\
\hline 2 & 0.28 & 0.32 & 0.34 & 0.41 & 0.30 & 0.080 \\
\hline 10 & 0.27 & 0.31 & 0.33 & 0.43 & 0.30 & 0.079 \\
\hline
\end{tabular}

Table 4. Values of the polarization resistance (in $\mathrm{M} \Omega \cdot \mathrm{cm}^{2}$ ) as a function of immersion time of thermally oxidized $\mathrm{Zr}$-Ti alloys in phosphate buffered saline solution acidified at $\mathrm{pH}=5.0 \pm 0.1$

\begin{tabular}{|c|c|c|c|c|c|c|}
\hline \multirow{2}{*}{ Immersion Time/h } & \multicolumn{6}{|c|}{ Oxidation Temperature $/{ }^{\circ} \mathrm{C}$} \\
\hline & 100 & 200 & 300 & 400 & 500 & 600 \\
\hline \multicolumn{7}{|c|}{ Zr-5Ti } \\
\hline 1 & 0.23 & 0.25 & 0.26 & 0.33 & 0.32 & 0.073 \\
\hline 2 & 0.21 & 0.23 & 0.25 & 0.34 & 0.30 & 0.071 \\
\hline 10 & 0.19 & 0.22 & 0.22 & 0.34 & 0.29 & 0.067 \\
\hline \multicolumn{7}{|c|}{$\mathrm{Zr}-25 \mathrm{Ti}$} \\
\hline 1 & 0.25 & 0.28 & 0.29 & 0.33 & 0.31 & 0.078 \\
\hline 2 & 0.25 & 0.27 & 0.28 & 0.34 & 0.29 & 0.077 \\
\hline 10 & 0.23 & 0.25 & 0.26 & 0.35 & 0.29 & 0.071 \\
\hline \multicolumn{7}{|c|}{$\mathrm{Zr}-45 \mathrm{Ti}$} \\
\hline 1 & 0.30 & 0.36 & 0.36 & 0.40 & 0.32 & 0.084 \\
\hline 2 & 0.29 & 0.35 & 0.35 & 0.42 & 0.32 & 0.083 \\
\hline 10 & 0.27 & 0.34 & 0.35 & 0.44 & 0.31 & 0.081 \\
\hline
\end{tabular}

Table 5. Values of the polarization resistance (in $\mathrm{M} \Omega \cdot \mathrm{cm}^{2}$ ) as a function of immersion time of thermally oxidized $\mathrm{Zr}$-Ti alloys in phosphate buffered saline solution acidified at $\mathrm{pH}=6.1 \pm 0.1$

\begin{tabular}{|c|c|c|c|c|c|c|}
\hline \multirow{2}{*}{ Immersion Time/h } & \multicolumn{6}{|c|}{ Oxidation Temperature $/{ }^{\circ} \mathrm{C}$} \\
\hline & 100 & 200 & 300 & 400 & 500 & 600 \\
\hline \multicolumn{7}{|c|}{ Zr-5Ti } \\
\hline 1 & 0.23 & 0.25 & 0.26 & 0.33 & 0.32 & 0.074 \\
\hline 2 & 0.22 & 0.24 & 0.25 & 0.34 & 0.31 & 0.071 \\
\hline 10 & 0.19 & 0.20 & 0.23 & 0.35 & 0.29 & 0.068 \\
\hline \multicolumn{7}{|c|}{$\mathrm{Zr}-25 \mathrm{Ti}$} \\
\hline 1 & 0.26 & 0.31 & 0.32 & 0.32 & 0.31 & 0.079 \\
\hline 2 & 0.25 & 0.31 & 0.32 & 0.34 & 0.30 & 0.076 \\
\hline 10 & 0.25 & 0.29 & 0.31 & 0.35 & 0.29 & 0.072 \\
\hline \multicolumn{7}{|c|}{$\mathrm{Zr}-45 \mathrm{Ti}$} \\
\hline 1 & 0.31 & 0.37 & 0.37 & 0.41 & 0.33 & 0.085 \\
\hline 2 & 0.29 & 0.36 & 0.37 & 0.42 & 0.32 & 0.084 \\
\hline 10 & 0.28 & 0.34 & 0.36 & 0.44 & 0.30 & 0.082 \\
\hline
\end{tabular}


Table 6. Values of the polarization resistance (in $\mathrm{M} \Omega \cdot \mathrm{cm}^{2}$ ) as a function of immersion time of thermally oxidized $\mathrm{Zr}$-Ti alloys in phosphate buffered saline solution acidified at $\mathrm{pH}=7.0 \pm 0.1$

\begin{tabular}{|c|c|c|c|c|c|c|}
\hline \multirow{2}{*}{ Immersion Time/h } & \multicolumn{6}{|c|}{ Oxidation temperature $/{ }^{\circ} \mathrm{C}$} \\
\hline & 100 & 200 & 300 & 400 & 500 & 600 \\
\hline \multicolumn{7}{|c|}{ Zr-5Ti } \\
\hline 1 & 0.24 & 0.25 & 0.27 & 0.34 & 0.32 & 0.078 \\
\hline 2 & 0.23 & 0.24 & 0.25 & 0.35 & 0.30 & 0.075 \\
\hline 10 & 0.19 & 0.21 & 0.22 & 0.35 & 0.28 & 0.069 \\
\hline \multicolumn{7}{|c|}{ Zr-25Ti } \\
\hline 1 & 0.27 & 0.31 & 0.35 & 0.32 & 0.31 & 0.079 \\
\hline 2 & 0.27 & 0.30 & 0.34 & 0.33 & 0.30 & 0.077 \\
\hline 10 & 0.25 & 0.29 & 0.32 & 0.36 & 0.30 & 0.072 \\
\hline \multicolumn{7}{|c|}{$\mathrm{Zr}-45 \mathrm{Ti}$} \\
\hline 1 & 0.31 & 0.36 & 0.38 & 0.41 & 0.31 & 0.087 \\
\hline 2 & 0.30 & 0.35 & 0.38 & 0.43 & 0.31 & 0.084 \\
\hline 10 & 0.28 & 0.35 & 0.37 & 0.46 & 0.30 & 0.081 \\
\hline
\end{tabular}

The observed increase in the corrosion resistance has also shown to occur in these alloys when treated at $500{ }^{\circ} \mathrm{C}$ using similar procedures [20,21,31]. Scanning electron microscopy (SEM) images of the cross section of the three materials subjected to similar thermal treatment have evidenced the formation of oxide layers on top of the metallic material, resulting in a more compact oxide coating that exhibited higher resistance against corrosion for the Zr-45Ti material [31].

Regarding the surface modification procedure, the corrosion resistance of the alloys was found to improve with the increase in the oxidation temperature up to $400-500{ }^{\circ} \mathrm{C}$, and it deteriorated quickly for higher temperatures, as illustrated by the data recorded for the samples treated at $600{ }^{\circ} \mathrm{C}$ in all cases. The causes for such deterioration remain still unknown and will require further investigation, although it can be speculated that the formation of a more porous structure with metal oxides of mixed oxidation state may occur. Finally, acidification of the test solution produced a very small effect on the corrosion resistance of the alloys, as it could be expected considering that the $\mathrm{pH}$ range covered in this work lies within the stability range of the passivating oxide layers developed on either titanium or zirconium pure metals [39], although slightly smaller $R_{\mathrm{p}}$ values were determined in solutions close to neutrality.

Table 7. Values of the polarization resistance (in $\mathrm{M} \Omega \cdot \mathrm{cm}^{2}$ ) as a function of immersion time of thermally oxidized $\mathrm{Zr}$-Ti alloys in phosphate buffered saline solution acidified at $\mathrm{pH}=8.1 \pm 0.1$

\begin{tabular}{|c|c|c|c|c|c|c|}
\hline \multirow{2}{*}{ Immersion Time/h } & \multicolumn{6}{|c|}{ Oxidation Temperature $/{ }^{\circ} \mathrm{C}$} \\
\hline & 100 & 200 & 300 & 400 & 500 & 600 \\
\hline \multicolumn{7}{|c|}{ Zr-5Ti } \\
\hline 1 & 0.17 & 0.19 & 0.24 & 0.31 & 0.29 & 0.067 \\
\hline 2 & 0.14 & 0.18 & 0.22 & 0.32 & 0.28 & 0.059 \\
\hline 10 & 0.09 & 0.15 & 0.18 & 0.34 & 0.26 & 0.053 \\
\hline \multicolumn{7}{|c|}{ Zr-25Ti } \\
\hline 1 & 0.19 & 0.21 & 0.25 & 0.31 & 0.30 & 0.071 \\
\hline 2 & 0.18 & 0.19 & 0.24 & 0.32 & 0.29 & 0.065 \\
\hline 10 & 0.15 & 0.17 & 0.22 & 0.35 & 0.27 & 0.058 \\
\hline \multicolumn{7}{|c|}{ Zr-45Ti } \\
\hline 1 & 0.21 & 0.22 & 0.27 & 0.32 & 0.31 & 0.078 \\
\hline 2 & 0.20 & 0.21 & 0.26 & 0.33 & 0.31 & 0.069 \\
\hline 10 & 0.18 & 0.19 & 0.24 & 0.36 & 0.29 & 0.061 \\
\hline
\end{tabular}




\subsection{In Vitro Monitoring of the Formation of Passivating Surface Layers on Zr-Ti Alloys}

The formation of the oxide surface layers on $\mathrm{Zr}$-Ti alloys upon immersion in simulated physiological solution was monitored by means of scanning electrochemical microscopy (SECM) operated in the amperometric feedback mode. In this way, the evolution of the electrochemical properties of these layers could be monitored in real time. Ferrocene-methanol was added to the Ringer physiological solution as redox mediator in order to monitor its diffusion-limited oxidation at the Pt microelectrode tip, which results in the limiting current, $i_{\text {lim }}$, sensed in bulk solution (see Figure $3 \mathrm{~A}$ ). When this reaction is performed in the proximity of the flat surface of the oxidized $\mathrm{Zr}$-Ti alloy sample, either the material will block the diffusion of the redox mediator towards the tip (that is, negative feedback at an insulating substrate, see Figure 3B), or regeneration of the redox mediator will occur if the material undergoes an electron transfer reaction (i.e., positive feedback at an electroactive substrate, see Figure 3C) [40]. Thus, respectively smaller or bigger faradaic currents will be recorded at the tip placed in the proximity of the investigated material compared to the value monitored in the bulk of the electrolyte. When irreversible electron transfer, under kinetic control, is attained at the surface, the response in SECM approach curves depicts an intermediate behavior between positive and negative feedback, depending on the geometry of the electrode and the electron transfer rate constant. Finally, in order to avoid the potential risk of fouling effects in the $\mathrm{Pt}$ probe due to components of the electrolyte, the simpler Ringer's solution was chosen instead of PBS, as to mimic the intracellular environment, acidified to $\mathrm{pH}$ 3 thereby simulating inflammatory conditions. The measurements were performed in the naturally aerated solution at $37^{\circ} \mathrm{C}$.

$\mathrm{Zr}-\mathrm{Ti}$ alloys subjected to thermal oxidation in the optimum temperature range were thus selected for this microelectrochemical characterization during immersion in simulated physiological solution. Figure 4A-C displays Z-approach curve results for the three thermally-oxidized Zr-Ti alloys measured during 1-day immersion in acidified Ringer's solution. $Y$-axis reflects the normalized current measured at each location, that is, the measured current divided by the current value registered in bulk solution. The $X$-axis gives the normalized vertical position, $L$, namely the $Z$ position divided by the Pt microdisk diameter $(d=10 \mu \mathrm{m})$. Results show that the behavior of the surfaces was primarily insulating, although dynamic evolution occur in all samples. The measured currents were observed to slightly increase within the first 3-5 h immersion, attaining maximum ranges after 140, 180, and 300 min immersion for the Zr-5Ti, Zr-25Ti, and Zr-45Ti specimens, respectively. After sufficiently long exposure (i.e., 20-24 h immersion), the surfaces became more insulating, directly related to thickening of the oxide-hydroxide layer formed on the surface of the alloys exposed to the aqueous environment. This feature is clearly observed from the general trend towards smaller normalized feedback currents measured at the tip located in the vicinity of the substrate (i.e., for small normalized tip-substrate separations) occurring for the longest immersion times in all cases.

These observations also differentiate between the three $\mathrm{Zr}$-Ti alloys in the early stages of immersion. Thus, whereas normalized currents smaller than one were always measured for the Zr-5Ti alloy (cf. Figure 4A), surfaces promoting higher tip currents, presumably due to partial conductivity/electron transfer efficiency, were observed for Zr-25Ti and Zr-45Ti (see the normalized currents higher than one in Figure 4B,C at the beginning of the experiment). Despite the observation of normalized currents greater than one for the Ti-rich alloys, it must be noticed that the Z-approach curves do not display the actual positive feedback behavior characteristic of conductive surfaces, as there was not a steady growth of the normalized current as the tip approached the substrate, ideally increasing towards infinite for normalized tip-substrate separations tending to zero. Instead, a mixed behavior between those corresponding to positive and negative feedback effects is observed. That is, as the tip traveled towards the substrate from the bulk of the electrolyte, the proximity of the surface was first noticed from the increase in the normalized current related to partial conductivity, and then eventually changed towards smaller normalized currents in the vicinity of the substrate. In addition, probe-approach curves measured after 3-5 h immersion for Zr-45Ti depict a continuous increment of the tip current at relatively large distances (i.e., 10 to 15 times the diameter of the Pt microdisk), with the same slope 
maintained until ca. $L=4$, which has been previously reported with the same alloys [19], but can hardly be ascribed or modeled considering exclusively feedback effects. Features eventually influencing the tip current must involve the generation of electro-active species diffusing towards the probe, either metal cations or complexes, or redox species catalytically formed at the surface of the metal following reactions of components of the electrolyte. The former is very unlikely, not only because of the stability of the passive films, but also considering that no titanium or zirconium-containing ion or complexes are expected to produce a measurable electrochemical signal at the given tip potential and weak acidic aqueous solution. However, (photo)catalytic reactions involving the generation of $\mathrm{H}_{2}$ or $\mathrm{H}_{2} \mathrm{O}_{2}$, oxidizable at the tip potential, cannot be discarded. Further evidence must be attained in order to investigate this effect, which otherwise should not compromise the surface stability.

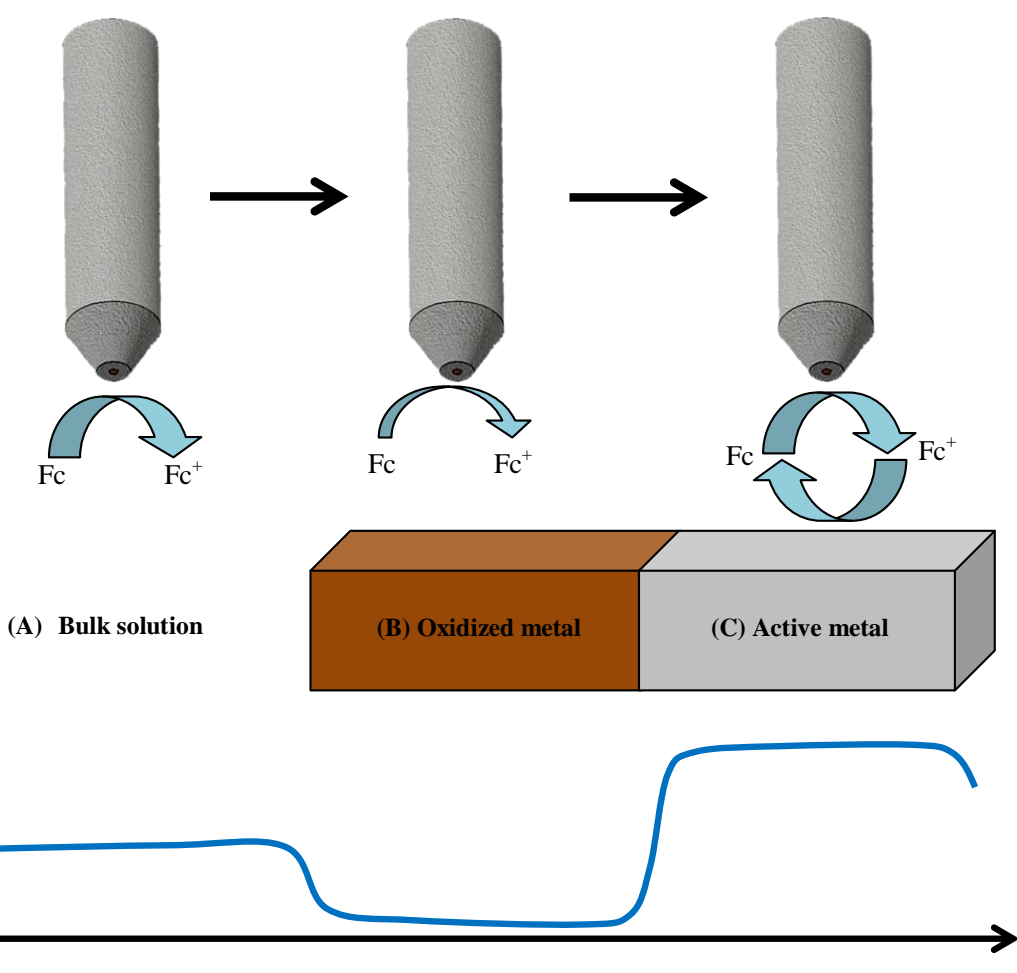

Tip movement along the surface

Figure 3. Limiting electrochemical responses for the tip current depending on the surface condition of the Zr-Ti alloys exposed to Ringer's solution during amperometric SECM operation using ferrocene-methanol $\left(\mathrm{FC}_{\mathrm{C}}\right.$ ) as redox mediator. (A) Current attains a diffusion-controlled limiting current value in bulk solution; (B) Negative feedback occurs over the oxide-covered surface, which blocks the diffusion pathways for Fc; (C) Positive feedback happens over conductive alloy surfaces that are able to regenerate ferrocene-methanol by reducing the ferrocenium ion $\left(\mathrm{Fc}^{+}\right)$formed at the tip.

The heterogeneity of the surface response was evaluated by conducting 2-D scans over a fixed random area of $500 \times 500 \mu \mathrm{m}^{2}$ dimensions for each specimen during the first $24 \mathrm{~h}$. Figure 5 displays representative area scans obtained during exposure of the materials to the acidified Ringer's solution. Notice that green color in all scans represent normalized current equal to 1 , that is, reproducing the same $i_{\text {lim }}$ current value attained for the diffusion-limited oxidation of the redox mediator in the bulk solution. Hence, normalized current values greater than one (e.g., yellow and red colors) indicate higher surface reactivity (i.e., positive feedback), whereas the blue color corresponds to more insulating properties (i.e., negative feedback).

The behavior of the three specimens dynamically changed during the first hours of immersion, moving towards more insulating character when samples were exposed over $20 \mathrm{~h}$. Zr-5Ti showed smoother current variations throughout the scanned area, whereas higher Ti content depicted regions 
with distinct reactivity. The response resembled closely that previously observed in the same solution at $25{ }^{\circ} \mathrm{C}$ [20]. However, the behavior differed with the addition of higher Ti content at the simulated body temperature in this work. Scans performed on Zr-25Ti exhibited one region with rather insulating properties in all scans (close to the drawn origin of coordinates), and only the first measurement showed a nearby area with higher reactivity, which progressively deactivated in following scans. Conversely, it was observed that the Zr-45Ti surface presented single locations with much higher activity towards electron exchange with the redox mediator. These spots contrasted with the main insulating properties exhibited by the surface, in particular after $24 \mathrm{~h}$ immersion.

It must be noticed that the conductivity characteristics in the feedback mode reflect the efficiency of the electron transfer reaction at the very site examined by the microelectrode for $L / d \rightarrow 0$, whereas wider screening of the surface occurs for longer distances. Then, normalized currents bigger than one in the Z-approach curves of Figure 4B,C indicate a surface that is not an efficient insulator, yet this phenomenon can also be explained considering the single active locations seen in the scans taken over the Zr-45Ti (cf. Figure 5). As result, from the observation of the Z-approach curves displayed in Figure 4A-C it can be concluded that the surface films formed on Zr-5Ti exhibit low efficiency for electron transfer even at short exposures to the electrolyte, and subsequent thickening of the bilayer oxide film leads to even more insulating characteristics. In contrast, the richer Ti alloys require exposure to the electrolyte to develop the surface oxide layers with insulating characteristics, namely $1 \mathrm{~h}$ and approximately 1 day for $\mathrm{Zr}-25 \mathrm{Ti}$ and $\mathrm{Zr}-45 \mathrm{Ti}$, respectively. The surface film developed on the $\mathrm{Zr}-25 \mathrm{Ti}$ surface would be the most insulating, with heterogeneities mostly depicting inert areas. Conversely, the oxide layer formed on the $\mathrm{Zr}$-45Ti was partially conductive at single locations, suggesting that the passive character could be locally broken to facilitate electron donation.

These SECM observations, depicting electrochemical heterogeneity and local passivity breakdown on the surface of $\mathrm{Zr}-45 \mathrm{Ti}$, apparently contradict the higher corrosion resistance exhibited by the Ti-enriched alloy from conventional averaging electrochemical (impedance) measurements. The developed oxide layer has shown to be equally or more inert in thermally oxidized $\mathrm{Zr}-45 \mathrm{Ti}$, compared to Zr-25Ti and Zr-5Ti, when exposed to phosphate buffer saline solution at $37^{\circ} \mathrm{C}$ (this work), neutral Ringer's solution at $37^{\circ} \mathrm{C}$ [31], and Ringer's acidified solution ( $\left.\mathrm{pH} 3\right)$ at $37{ }^{\circ} \mathrm{C}$ [20]. However, SECM results obtained in the feedback mode reflect the ability of the sample to transfer electrons via heterogeneous electron exchange reactions at its surface, rather than the release of metal cations from the anodic degradation of the material. That is, the origin of the electrons collected by the ferrocenium ions does necessarily stem from the anodic dissolution of Ti or Zr. Instead, ferrocenium ions may promote the formation of oxides, thus accelerating the thickening of the oxide layer, providing that the single point location at which tip current increases behaves as electrically conductive and kinetically active for the heterogeneous electron donation. This thickening process results in a final surface state which behaves primarily insulating after $24 \mathrm{~h}$ immersion, supporting the formation of a protective layer. In addition, it is feasible that, if the excitation of electrons from the valence band to the conduction band occurs in such semiconductor material surfaces under illumination, electrons may be either collected following water splitting mechanism, or by the ferrocenium ions instead. All these early-stage phenomena might occur heterogeneously during the development of the passive layer, attaining homogeneous insulating and protective character after sufficiently long immersion time. Given the presence of redox proteins in the real physiological media [41,42], the ability of a metal implant to exchange electrons on the surface, and eventually promote the alteration of such biomolecules during the early stages of the implantation procedure, is regarded as critical and needs to be taken into consideration in regard to the biocompatibility of a newly proposed biomaterial. 

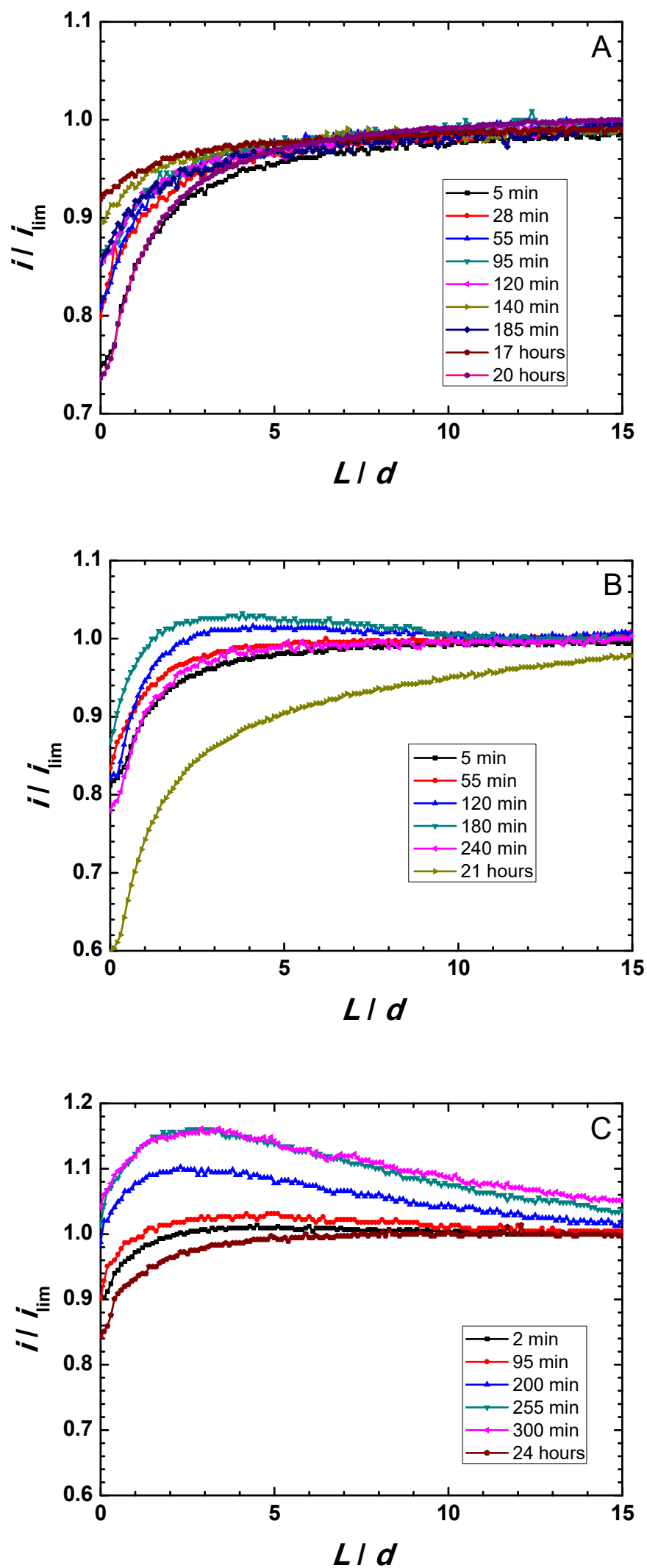

Figure 4. Feedback mode $\mathrm{Z}$-approach curves on oxidized binary $\mathrm{Zr}$-Ti alloys immersed in acidified Ringer's solution at $37^{\circ} \mathrm{C}$. (A) Zr-5Ti; (B) Zr-25Ti; (C) Zr-45Ti. 
Zr-5Ti
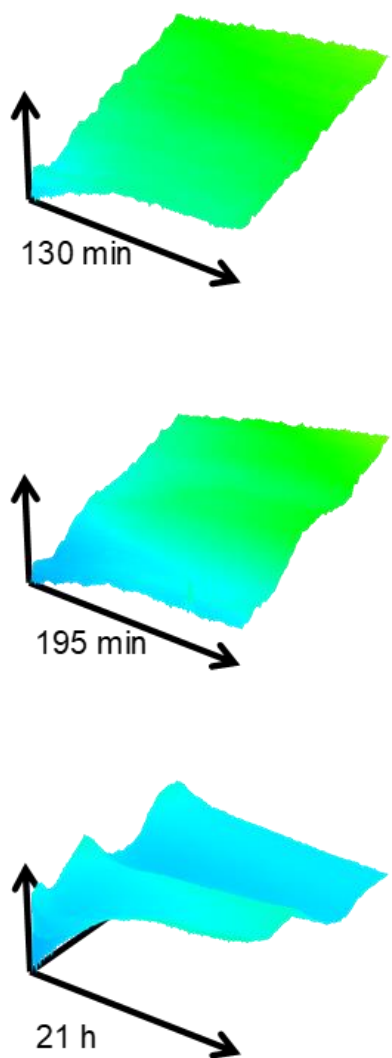
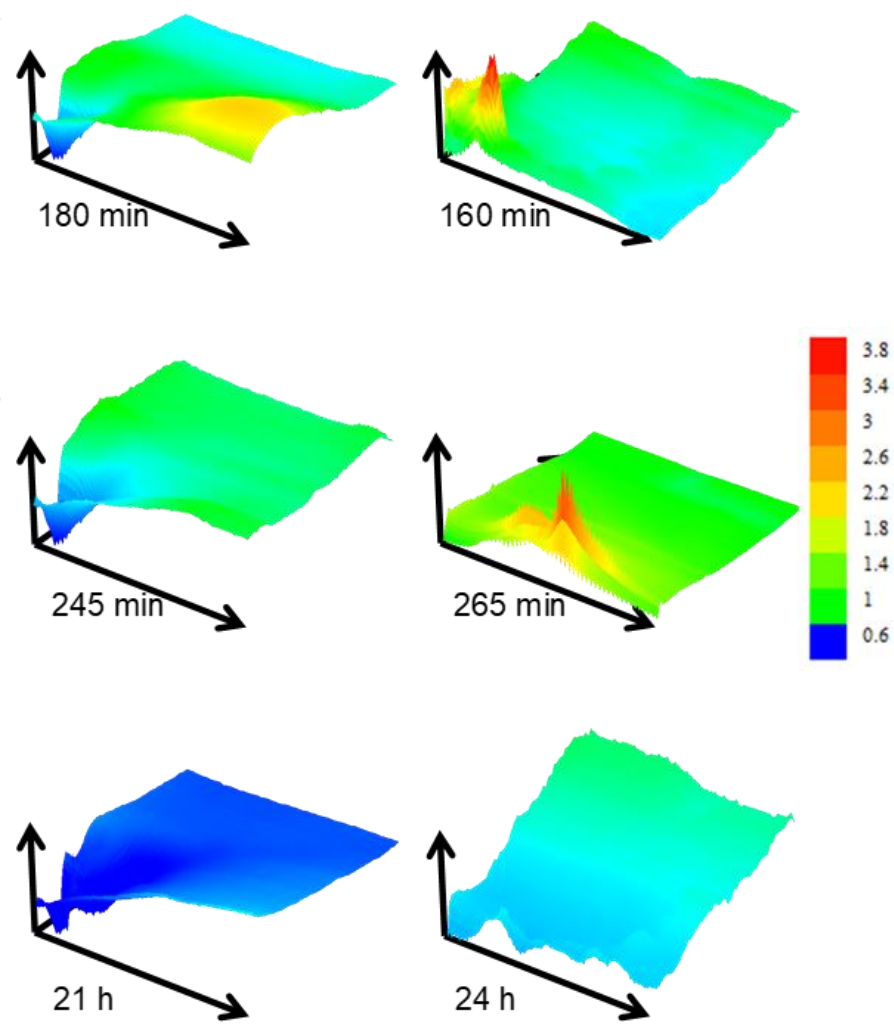

$24 \mathrm{~h}$

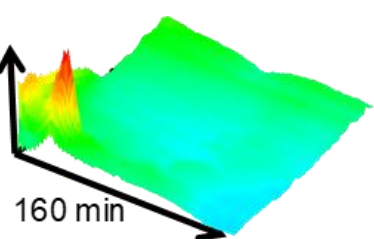

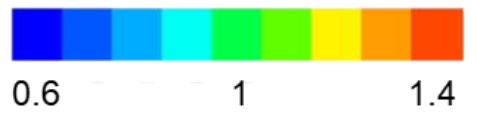

Zr-45Ti

1.4

Figure 5. Representative feedback mode 2-D scans of $500 \times 500 \mu \mathrm{m}^{2}$ dimension on oxidized binary $\mathrm{Zr}$-Ti alloys immersed in acidified Ringer's solution at $37^{\circ} \mathrm{C}$. Images in a column were obtained over the same sample and area, indicated at the top of the figure. Time immersion is given below each scan. The color scale gives the normalized current in all scans except for the scan measured on Zr-45Ti after $265 \mathrm{~min}$, which is plotted with its own color scale.

\section{Conclusions}

Corrosion resistance is not exclusively conferred to the binary $\mathrm{Zr}-\mathrm{Ti}$ alloys by thin oxide films formed during the thermal oxidation treatment in air, but they operate in combination with the hydrated oxide films formed upon immersion in the simulated physiological environment. The reported ageing process of the surface oxide layers in the simulated physiological solution is more efficient as to enhance corrosion resistance for the alloys with higher Ti content, which may be related to our previous report of thicker and more compact oxide layers formed on non-treated Zr-45Ti upon exposure to Ringer's solution [31]. Finally, as regards to potential use of the binary Zr-Ti alloys as implant materials with high corrosion resistance, it is recommended that the samples are previously subjected to a thermal oxidation treatment in air, followed by exposure to an artificial physiological solution for $24 \mathrm{~h}$.

The present work demonstrates that multiscale electrochemical characterization can be successfully employed to monitor the corrosion characteristics of binary $\mathrm{Zr}$-Ti alloys subjected to surface modification. The powerful combination of electrochemical techniques allowed both to select the optimal surface 
processing conditions as well as to characterize the surface reactivity of the surface layers formed on the treated materials. As a result, the following conclusions were derived:

(1) The thermal oxidation in air increased the corrosion resistance of binary Zr-Ti alloys, the effect being especially beneficial when performed at $500^{\circ} \mathrm{C}$.

(2) Upon immersion in the simulated physiological solution, the formation of passivating oxide layers on the surface of the alloys occurs. The observation of two time-constants in the electrochemical impedance spectra of the samples exposed to simulated physiological solution at $37^{\circ} \mathrm{C}$ reveal the formation of a bilayer surface film. The results are consistent with a thin inner compact layer and a thicker, although unsealed, outer layer.

(3) Additions of Ti to $\mathrm{Zr}$ (from 5 to $45 \mathrm{wt} . \%$ ) contribute to the formation of a more corrosion resistant surface film on the alloys.

(4) SECM characterization in the feedback mode showed that insulating characteristics of the passivating oxide layers on the binary Zr-Ti alloys are progressively developed with ageing in the simulated physiological environment. Longer exposures are required for the alloys with higher Ti contents. The surface formed on $\mathrm{Zr}$-Ti alloy with $45 \mathrm{wt} . \%$ content of Ti was observed to be heterogeneous with single active locations dynamically evolving on the surface.

(5) Thinner and more compact oxide layers are expected in the presence of higher Ti content, which concurrently promotes the electron transfer phenomena heterogeneously during the early stages of exposure in the physiological environment. Such phenomena may influence the biocompatibility of the alloys when exposed to real or in vitro operation conditions.

Author Contributions: Conceptualization, D.M., L.C.T., and R.M.S.; data curation, G.B., R.R.-R., and L.C.F.-M.; formal analysis, J.J.S. and J.I.; funding acquisition, D.M. and R.M.S.; investigation, D.M., L.C.T., and J.I.; methodology, G.B., J.J.S., and J.I.; project administration, L.C.T. and R.M.S.; resources, D.M. and R.M.S.; software, L.C.F.M.; supervision, D.M. and R.M.S.; validation, J.J.S., L.C.T., and R.M.S.; visualization, L.B., L.C.T., and R.R.-R.; writing-original draft, L.B., L.C.T., and J.I.; writing—review and editing, L.C.T., L.B., J.J.S., J.I., and R.M.S. All authors have read and agreed to the published version of the manuscript.

Funding: This work was supported partially by the Romanian National Authority for Scientific Research (CNCS-UEFISCDI, Bucharest, Romania; project no. PN-II-IDPCE-2011-3-0218), and by the Spanish Ministry of Economy and Competitiveness (MINECO, Madrid, Spain) and the European Regional Development Fund (Brussels, Belgium; project no. CTQ2016-80522-P).

Conflicts of Interest: The authors declare no conflict of interest.

\section{References}

1. Williams, D.F. Biocompatibility of clinical implant materials. In Biocompatibility of Clinical Impact Materials; Williams, D.F., Ed.; CRC Press: Boca Raton, FL, USA, 1981; Volume 1, p. 9.

2. Kovacs, P.; Davidson, J.A. Chemical and electrochemical aspects of the biocompatibility of titanium and its alloys. In Medical Applications of Titanium and Its Alloys: The Materials and Biological Issues; Brown, S.A., Lemons, J.E., Eds.; ASTM: West Chonshohocken, PA, USA, 1996; p. 163.

3. ASM International. ASM Handbook, Corrosion, 9th ed.; ASM International: Metals Park, OH, USA, 1987; Volume 13.

4. Geetha, M.; Singh, A.K.; Asokamani, R.; Gogia, A.K. Ti Based biomaterials, the ultimate choice for orthopaedic implants-A review. Prog. Mater. Sci. 2009, 54, 397-425. [CrossRef]

5. Solar, R.J. Corrosion resistance of titanium surgical implant alloys, a review. Corrosion and degradation of implant materials. In Corrosion and Degradation of Implant Materials; Syrett, S.C., Acharya, A., Eds.; ASTM Special Technical Publication STP 684: Philadelphia, PA, USA, 1979; pp. 259-273.

6. Pan, J.; Thierry, D.; Leygraf, C. Electrochemical impedance spectroscopy study of the passive oxide film on titanium for implant application. Electrochim. Acta 1996, 41, 1143-1153. [CrossRef]

7. Burstein, G.T.; Liu, C.; Souto, R.M. The effect of temperature on the nucleation of corrosion pits on titanium in ringer's physiological solution. Biomaterials 2005, 26, 245-256. [CrossRef]

8. Okazaki, Y.; Gotoh, E. Comparison of metal release from various metallic biomaterials in vitro. Biomaterials 2005, 26, 11-21. [CrossRef] 
9. Hallab, N.J.; Anderson, S.; Caicedo, M.; Brasher, A.; Mikecz, K.; Jacobs, J.J. Effects of soluble metals on human peri-implant cells. J. Biomed. Mater. Res. A 2005, 74, 124-140. [CrossRef]

10. Piazza, S.; Lo Biundo, G.; Romano, M.C.; Sunseri, C.; Di Quarto, F. In situ characterization of passive films on Al-Ti alloy by photocurrent and impedance spectroscopy. Corros. Sci. 1998, 40, 1087-1108. [CrossRef]

11. Rao, S.; Okazaki, Y.; Tateishi, T.; Ushida, T.; Ito, Y. Cytocompatibility of new Ti alloy without $\mathrm{Al}$ and V by evaluating the relative growth ratios of fibroblasts L929 and osteoblasts MC3T3-E1 cells. Mater. Sci. Eng. C 1997, 4, 311-314. [CrossRef]

12. Michelle Grandin, H.; Berner, S.; Dard, M. A review of titanium zirconium (TiZr) alloys for use in endosseous dental implants. Materials (Basel) 2012, 5, 1348-1360. [CrossRef]

13. Altuna, P.; Lucas-Taulé, E.; Gargallo-Albiol, J.; Figueras-Álvarez, O.; Hernández-Alfaro, F.; Nart, J. Clinical evidence on titanium-zirconium dental implants: a systematic review and meta-analysis. Int. J. Oral Maxillofac. Surg. 2016, 45, 842-850. [CrossRef] [PubMed]

14. Hsu, H.C.; Wu, S.C.; Sung, Y.C.; Ho, W.F. The structure and mechanical properties of as-cast Zr-Ti alloys. J. Alloy. Compd. 2009, 488, 279-283. [CrossRef]

15. Liang, S.X.; Yin, L.X.; Zhou, Y.K.; Feng, X.J.; Ma, M.Z.; Liu, R.P.; Tan, C.L. Abnormal martensitic transformation of high Zr-containing Ti alloys. J. Alloy. Compd. 2014, 615, 804-808. [CrossRef]

16. Zhou, Y.K.; Liang, S.X.; Jing, R.; Jiang, X.J.; Ma, M.Z.; Tan, C.L.; Liu, R.P. Microstructure and tensile properties of hot-rolled Zr50-Ti50 binary alloy. Mater. Sci. Eng. A 2015, 621, 259-264. [CrossRef]

17. Oliveira, N.T.C.; Biaggio, S.R.; Rocha-Filho, R.C.; Bocchi, N. Electrochemical studies on zirconium and its biocompatible alloys Ti-50Zr at.\% and Zr-2.5Nb wt.\% in simulated physiologic media. J. Biomed. Mater. Res. A 2005, 74, 397-407. [CrossRef]

18. Chelariu, R.; Mareci, D.; Munteanu, C. Preliminary electrochemical testing of some Zr-Ti alloys in $0.9 \% \mathrm{NaCl}$ solution. Mater. Corros. 2013, 64, 585-591. [CrossRef]

19. Bolat, G.; Izquierdo, J.; Santana, J.J.; Mareci, D.; Souto, R.M. Electrochemical characterization of ZrTi alloys for biomedical applications. Electrochim. Acta 2013, 88, 447-456. [CrossRef]

20. Izquierdo, J.; Bolat, G.; Mareci, D.; Munteanu, C.; González, S.; Souto, R.M. Electrochemical behaviour of ZrTi alloys in artificial physiological solution simulating in vitro inflammatory conditions. Appl. Surf. Sci. 2014, 313, 259-266. [CrossRef]

21. Mareci, D.; Bolat, G.; Cailean, A.; Santana, J.J.; Izquierdo, J.; Souto, R.M. Effect of acidic fluoride solution on the corrosion resistance of ZrTi alloys for dental implant application. Corros. Sci. 2014, 87, 334-343. [CrossRef]

22. Akimoto, T.; Ueno, T.; Tsutsumi, Y.; Doi, H.; Hanawa, T.; Wakabayashi, N. Evaluation of corrosion resistance of implant-use Ti-Zr binary alloys with a range of compositions. J. Biomed. Mater. Res. B Appl. Biomater. 2018, 106, 73-79. [CrossRef]

23. Leucht, P.; Kim, J.-B.; Wazen, R.; Currey, J.A.; Nanci, A.; Brunski, J.B.; Helms, J.A. Effect of mechanical stimuli on skeletal regeneration around implants. Bone 2007, 40, 919-930. [CrossRef]

24. Abdel-Hady Gepreel, M.; Niinomi, M. Biocompatibility of Ti-alloys for long-term implantation. J. Mech. Behav. Biomed. Mater. 2013, 20, 407-415. [CrossRef]

25. Fahey, J.; Holmes, D.; Yau, T.L. Evaluation of localized corrosion of zirconium in acidic chloride solutions. Corrosion 1997, 53, 54-61. [CrossRef]

26. Rosalbino, F.; MacCiò, D.; Saccone, A.; Angelini, E.; Delfino, S. Stability of the passive state of Zr- $\mathrm{Nb}$ crystalline alloys. Mater. Corros. 2012, 63, 580-585. [CrossRef]

27. Rondelli, G.; Vicentini, B. Effect of copper on the localized corrosion resistance of Ni-Ti shape memory alloy. Biomaterials 2002, 23, 639-644. [CrossRef]

28. García-Alonso, M.C.; Saldaña, L.; Vallés, G.; González-Carrasco, J.L.; González-Cabrero, J.; Martínez, M.E.; Gil-Garay, E.; Munuera, L. In vitro corrosion behaviour and osteoblast response of thermally oxidised Ti6Al4V alloy. Biomaterials 2003, 24, 19-26. [CrossRef]

29. Ferreira, E.A.; Rocha-Filho, R.C.; Biaggio, S.R.; Bocchi, N. Corrosion resistance of the Ti-50Zr at.\% alloy after anodization in different acidic electrolytes. Corros. Sci. 2010, 52, 4058-4063. [CrossRef]

30. Milošev, I.; Kapun, B. The corrosion resistance of Nitinol alloy in simulated physiological solutions. Part 2: The effect of surface treatment. Mater. Sci. Eng. C 2012, 32, 1068-1077. [CrossRef] 
31. Bolat, G.; Izquierdo, J.; Mareci, D.; Sutiman, D.; Souto, R.M. Electrochemical characterization of ZrTi alloys for biomedical applications. Part 2: The effect of thermal oxidation. Electrochim. Acta 2013, 106, 432-439. [CrossRef]

32. Cui, W.F.; Shao, C.J. The improved corrosion resistance and anti-wear performance of Zr-XTi alloys by thermal oxidation treatment. Surf. Coatings Technol. 2015, 283, 101-107. [CrossRef]

33. Mareci, D.; Bolat, G.; Istrate, B.; Munteanu, C.; Cailean, A. Effect of thermal oxidation on electrochemical corrosion behaviour of ZrTi alloys for dental applications. Mater. Corros. 2015, 66, 1529-1535. [CrossRef]

34. Izquierdo, J.; González-Marrero, M.B.; Bozorg, M.; Fernández-Pérez, B.M.; Vasconcelos, H.C.; Santana, J.J.; Souto, R.M. Multiscale electrochemical analysis of the corrosion of titanium and Nitinol for implant applications. Electrochim. Acta 2016, 203, 366-378. [CrossRef]

35. Lavos-Valereto, I.C.; Wolynec, S.; Ramires, I.; Guastaldi, A.C.; Costa, I. Electrochemical impedance spectroscopy characterization of passive film formed on implant Ti-6Al-7Nb Alloy in Hank's solution. J. Mater. Sci. Mater. Med. 2004, 15, 55-59. [CrossRef] [PubMed]

36. Vasilescu, C.; Drob, S.I.; Neacsu, E.I.; Mirza Rosca, J.C. Surface analysis and corrosion resistance of a new titanium base alloy in simulated body fluids. Corros. Sci. 2012, 65, 431-440. [CrossRef]

37. Duarte, L.T.; Biaggio, S.R.; Rocha-Filho, R.C.; Bocchi, N. Surface characterization of oxides grown on the Ti-13Nb-13Zr alloy and their corrosion protection. Corros. Sci. 2013, 72, 35-40. [CrossRef]

38. Cvijović-Alagić, I.; Cvijović, Z.; Bajat, J.; Rakin, M. Composition and processing effects on the electrochemical characteristics of biomedical titanium alloys. Corros. Sci. 2014, 83, 245-254. [CrossRef]

39. Pourbaix, M. Atlas of Electrochemical Equilibria in Aqueous Solutions; Pourbaix, M., Ed.; National Association of Corrosion Engineers: Houston, TX, USA, 1974.

40. Bard, A.J.; Fan, F.R.F.; Kwak, J.; Lev, O. Scanning Electrochemical Microscopy. Introduction and principles. Anal. Chem. 1989, 61, 132-138. [CrossRef]

41. Yun, Y.H.; Turitto, V.T.; Daigle, K.P.; Kovacs, P.; Davidson, J.A.; Slack, S.M. Initial hemocompatibility studies of titanium and zirconium alloys: Prekallikrein activation, fibrinogen adsorption, and their correlation with surface electrochemical properties. J. Biomed. Mater. Res. 1996, 32, 77-85. [CrossRef]

42. Wan, G.; Lv, B.; Jin, G.; Maitz, M.F.; Zhou, J.; Huang, N. Direct correlation of electrochemical behaviors with anti-thrombogenicity of semiconducting titanium oxide films. J. Biomater. Appl. 2014, 28, 719-728. [CrossRef]

(C) 2020 by the authors. Licensee MDPI, Basel, Switzerland. This article is an open access article distributed under the terms and conditions of the Creative Commons Attribution (CC BY) license (http://creativecommons.org/licenses/by/4.0/). 